\title{
LINGUISTICS-BASED PHARMACEUTICAL PRODUCT NAMING METHODS: A MORPHOLOGICAL STUDY ON OVER THE COUNTER MEDICINE PRODUCTS IN INDONESIA
}

\author{
KASNO PAMUNGKAS ${ }^{1 *}$, RIZKY ABDULAH ${ }^{2}$ \\ ${ }^{1}$ Department of Linguistics, Faculty of Cultural Sciences, Universitas Padjadjaran, Indonesia. ${ }^{2}$ Department of Pharmacology and Clinical \\ Pharmacy, Faculty of Pharmacy, Universitas Padjadjaran, Indonesia. Email: kasno.pamungkas@unpad.ac.id
}

Received: 1 November 2016, Revised and Accepted: 24 January 2017

\section{ABSTRACT}

Objective: Objective of the study was to assess the linguistics-based product naming methods of some over the counter (OTC) medicine in Indonesia and their impacts to companies and consumers.

Methods: The study uses qualitative descriptive method carried out among 57 data randomly taken from the lists of OTC medicine issued by some pharmaceutical companies in Indonesia. The data were classified into the morphological theory regarding the word formation methods which discusses the process of forming the words, product naming strategy and theory of OTC products taken from FDA.

Results: This study shows that a proper and precise OTC medicine naming method can employ the linguistics aspect especially word formation theory to describe the kinds, characteristics, and the usage of the products. The word formation methods found in this study are blending $59.6 \%$ ( 34 products), clipping $1.7 \%$ ( 1 product), compounding 3.5\% ( 2 products), and unknown method 35\% (20 products). In the context of product naming strategies, $65 \%$ of the data employs superiority and product advantage emphasizes, usability or ability conducted by the product, and showing what can be obtained using the product. While the remains 35\% does not employ the product naming strategies properly except easy to pronounce. The unknown OTC medicine naming method is not on target with the OTC medicine consumers in Indonesia since the meaning of the product names are not easily recognized from their namings.

Conclusion: From the results, it can be underlined that the product naming processes should be in line with the product naming strategies to have effective and understandable names of OTC medicine. There are 59.6\% using blending naming, 1.7\% using clipping, 3.5\% using compounding, and $35 \%$ using unknown method. In the context of product naming strategies, $65 \%$ employs superiority and product advantage emphasizes, usability or ability conducted by the product, showing what can be obtained using the product; $35 \%$ does not employ the product naming strategies properly except easy to pronounce. The ineffective and not understandable names of OTC could lead to disadvantages for both companies and consumers.

Keywords: Word formation, Product naming strategies, Over the counter medicine, Effective naming.

(C) 2017 The Authors. Published by Innovare Academic Sciences Pvt Ltd. This is an open access article under the CC BY license (http://creativecommons. org/licenses/by/4. 0/) DOI: http://dx.doi.org/10.22159/ajpcr.2017.v10s2.19512

\section{INTRODUCTION}

Researches on morphology are found in almost all languages in the world, in which they are classified into both pure or microlinguistics and applied studies. This research, however, has distinction compared to the former and existing ones since it involves another discipline, namely pharmacy, especially in naming the medicine as one of the pharmaceutical products. Language, in this study, is employed as the identity marker of products. On the other hand, it does not only function to identify the products but also indirectly to advertise them. In this case, language plays an important role in naming the products. It can be seen from the use of language in the form of a specific word or phrase as the name of pharmaceutical products. Language is used as a product name since the product only has a physical form, then it can be characterized by giving it identity with good naming both the form and meaning. In other words, language can communicate the types and characteristics of a product.

The use of language as a product name, whether in English, Indonesian or other languages, is one of language nature as a means of communication although in a country where the language is not spoken in everyday life, such as English in Indonesia and some other countries. This indicates that the use of language is not only limited to communicate verbally or textually but also has penetrated into the field of advertising such as in product name.

The name of a product, commonly known as brand, cannot be separated from the type of object or goods produced by a company since the brand should inform the characteristics of a product. Without a name or brand, a product will not be known by consumers. Language elements that play an important role in a product naming or brand are words and phrases. Most companies use words and phrases in naming their products. Words and phrases used as a product name is varied enough, for example, English-Indonesian, English and some other foreign language, not even the least of which is a mixture of two languages in naming products [1].

This study focuses on the naming methods of a pharmaceutical product in the perspective of linguistics. The objects of this study are over the counter (OTC) medicines in Indonesia. Why are the OTC medicine used as the objects? OTC medicine is the types of medicines that sold freely without prescription. In addition, they can be found not only in the medicine store with some pharmacist or his/her assistants but also found in supermarket, minimarket, or mini shop that do not have proper knowledge of medicinal information and ethics of pharmacology. The consumer freely chooses the OTC medicine according to their needs. Therefore, it is necessary that the consumers get a clear information about the OTC medicine since they should select by themselves without prescription or suggestions from which they purchase them. Although they could get the OTC medicine information from its label, but label is not branding since it is provided by all product that does not differentiate the product, branding is the product name. Started with these rationales, this study is focused on the following objectives.

\section{Aims}

1. To assess the OTC medicine naming processes based on linguistics perspective 
2. To compare the effective and informative product naming strategies of the OTC medicine between the naming with linguistics perspective and unknown method.

\section{METHODS}

This study uses the theory of morphology, especially word formation which discusses the process of forming the words [2-4], product naming strategies [5,6], and theory of OTC products [7]. A proper and precise OTC drug naming method can employ the linguistics aspect especially word formation theory to describe the kinds, characteristics, and the usage of the products. The word formation processes found in this study are blending, clipping, compounding, and some data show none of the morphological processes and then it is called unknown method. Then, the meaning analysis used is based on lexical and grammatical meaning. By understanding the word formation process used as the OTC drug naming methods, consumers can recognize the products more easily.

\section{Word formation: A linguistics perspective}

As an important element in naming the OTC medicine, word does not come incidentally but it has its origins, i.e., word formation. Word is a unit of language that can stand on its own. It derives from single or combined morpheme $[8,9]$. As a component of language, word undergoes a process of formation, hereinafter referred to process of forming words or word formation, which is one of the morphological studies. The process of forming the words explains how a word is formed.

The word formation "is the branch of the science of language which studies the pattern on which a language forms new lexical units, i.e., words [3]."

The word formation in English is divided into several types [4], namely:

1. Derivation, a word formed by adding the suffix either in the form of a prefix or suffix, such as government and happiness.

2. Compounding, a word formed by combining two free words to produce a new meaning, for example: Girlfriend and lifeguard, blackboard.

3. The acronym, word formation that occurs by taking the first letter or sound next to each word and combine them into one word, example: NATO, ABRI, and UN.

4. Back formation, analogy process of a new word by reducing affixes in the word, e.g.,: Television $\rightarrow$ televise.

5. Blending is a combination of parts of two words, usually the beginning of the first word and the final part of the second word, for example: Smoke + fog: Smog and breakfast + lunch: Brunch.

6. Clipping, shortening the word by cutting the front (aphesis), middle (syncope), or end of the word (apocope). Examples: Van of the caravan, ne'er than never, dorm from the dormitory.

7. Coinage, word formed without the use of methods or other word elements but the words are formed from existing ones, is usually a word that has been popular and is intended to maintain the popularity of the word or to make it more popular. This word formation is widely used in the naming of products, such as Kodak and Exxon.

8. Functional shift, forming words by changing the word class without changing the form of the word, e.g.: Run, laugh used both as a noun and a verb.

9. Morphological misanalysis, words formed with familiar words but there is no obvious reason of their formation, for example: The suffix - burger is misanalysis from hamburger word formed from ham + burger. While hamburger is a fragment of a hamburger steak. This misanalysis is seen from the wide range of products such as cheeseburger, salmonburger, and beefburger

10. Proper names, words derive from the name of a person attached to name of place, street, inventions, e.g.: City of Washington DC derived from the name of George Washington, and the District of Columbia from Christopher Columbus.

\section{Product naming strategy}

To create the personality of a product, the company must establish a product name. To name a product effectively and informatively, it must be accompanied with appropriate strategies such as it is easy to pronounce, easy to remember, and indicates the functionality and usability of the product. A product name is either able to describe or characterize the product [5]. Naming the product often:

1. Referring to the name of the company, which deals with connotations posed by popularity, superiority, or the excellence of the company issuing the products. Therefore, the consumers, knowing the name of the product, are directly affected by the popularity and quality of the company's products, for example: Armani, Benetton, Folger's, Louis Vuitton.

2. Referring to an imaginary or made-up personality and causing a particular image associated to the name, for example: Wendys refer to image of a young friendly girl, Mr. Clean poses a strong image of a worker;

3. Referring to the aspects of nature and giving the product quality related to nature, for example: Tide, Aqua, and Surf.

4. Emphasizing superiority and product advantages, e.g., Maxilight, Superfresh, and Ultralite.

5. Expressing usability or ability conducted by the product, e.g., Flow quick and easy wipe.

6. Showing what can be obtained using the product, e.g., Close-Up and No Sweat Deodorant.

7. Combining words that have joint meaning of product composition through the compounding: Yogourt $\rightarrow$ yogurt + gourmet, mountea $\rightarrow$ mountain + tea, dll

Name of the product can do more than just identify a product. It is formed to create such a product labeling system. At the level of practical information, product naming has a denotative function, which directs consumers to identify what products to buy. On the connotative level, product name raises the image going beyond more than just identifying the function of the product. For instance: Nike, denotatively the name directs consumers to identify that the product is sport equipment. However, connotatively the name of the company will give us the aura of popularity and advantages of the product quality rather than just the name of the product used $[5,6]$.

\section{OTC medicine}

Over-the-counter medicine or OTC is nonprescription medicine which refers to medicine that can be purchased without a prescription. They are safe and effective when you follow the directions on the label and as directed by your health care professional [7].

Further, the existence of OTC is stated formally according to the following:

“... today's OTC medicines offer greater opportunity to treat more of the aches and illnesses most likely to appear in our later years. As we live longer, work longer, and take a more active role in our own health care, the need grows to become better informed about self-care. The best way to become better informed-for young and old alike-is to read and understand the information on OTC labels. Next to the medicine itself, label comprehension is the most important part of self-care with OTC medicines. With new opportunities in self-medication come new responsibilities and an increased need for knowledge. FDA and the Consumer Healthcare Products Association have prepared the following information to help Americans take advantage of self-care opportunities [7].

The contents of the label when taking an OTC medicine [7] are as follows:

- Product name

- "Active ingredients": Therapeutic substances in medicine

- "Purpose": Product category (such as antihistamine, antacid, or cough suppressant)

- "Uses": Symptoms or diseases the product will treat or prevent

- "Warnings": When not to use the product, when to stop taking it, when to see a doctor, and possible side effects 
- "Directions": How much to take, how to take it, and how long to take it

- "Other information": Such as storage information

- "Inactive ingredients": Substances such as binders, colors, or flavoring.

It can be seen that "Product name" is placed as the most important part of OTC label which means that it plays a significant role in OTC both for the consumers and companies.

\section{Research methods}

The method used in this research is analytical descriptive one. Qualitative research assumes that all knowledge is relative that there is a subjective element to all knowledge and research and that holistic ungeneralizable studies are justifiable [10]. The aim of descriptive research is to describe condition and phenomenon. Therefore, there is no right and wrong emphasis in the study but it intends to describe the phenomenon of the OTC medicine naming and its intentions contained in the product name. In addition to the descriptive, this research is also an analytical one, i.e., to discuss and analyze the word formation of the product name and their strategies of naming [11]. The authors obtained data from some websites of the medicine company in Indonesia. The data obtained are selected into the four OTC medicines for ailments mostly found in Indonesia namely cold and cough remedies, antacid and antiulcerant, analgesic and antipyretic, and antidiarrheal. Then, the data are taken randomly into 57. They are grouped into types of word formation, and then analyzed according to word formation as well as the product naming strategies.

\section{RESULTS AND DISCUSSION}

\section{Blending}

The naming of OTC medicines through blending process is by combining the parts of two words which is usually the beginning of the first word and the final part of the second word. From 57 data of OTC medicines, there are 34 names employing this name formation. They are shown in Table 1.

The OTC medicines above are formed with blending method, by combining the parts of the first word and another part of the second word. At least, there are four classifications of OTC medicine blending based on the elements of the word. First, they blend the name of company and the name of active ingredients such as Konidin, Konimag, Bodrex, Bekarbon, and Paramex. Diagram 1 shows the illustration of such product naming formation.

The OTC medicine naming method above is in line with the product naming strategy, i.e., referring to the name of the company, which deals with connotations posed by popularity, superiority, or the excellence of the company issuing the products. The illustration informs that this OTC name contains magnesium as the active ingredient for antacids and antiulcerant which is produced by Konimex. Therefore, this OTC medicine is promoted that it is produced by Konimex, one of the superior and excellent company in Indonesia.

Second, it is also found blending of the company name with the use of the medicine, for instance, Sanaflu, Neosanmag, and Fitodiar. It is strengthened with expressing usability or ability conducted by the product. Diagram 2 shows the description of such product naming formation.

The illustration informs that this OTC name is used as the influenza remedy which is produced by Sanbe Farma, one of the superior pharmacy companies. It is hope, then, that the consumers are influenced by the popular name of Sanbe Farma. They who need OTC medicine for influenza issued by a credible company will choose Sanaflu.

According to this data, these two OTC naming strategies tend to be employed by some superior pharmaceutical industries in Indonesia such as Kalbe Farma for Bekarbon, Sanbe Farma for Sanaflu and Neosanmag, Fito Farma for Fitodiar, Konimex for Konidin, Termorex, and Paramex.

Third, blending of OTC medicine naming involves the name of ailment and action that can be conducted by the products; they are Diapet,
Table 1: List of OTC medicines with blending process in product naming

\begin{tabular}{lllll}
\hline Methods & $\begin{array}{l}\text { Cough } \\
\text { and cold }\end{array}$ & Antacid & Influenza & Antidiarrheal \\
\hline Blending & Sanaflu & Magasida & Supraflu & Bekarbon \\
& Konidin & Neosanmag & Procold & Entrostop \\
Decolsin & Promag & Bodrex & Diapet \\
& Fludexin & Mylanta & Paramex & Diatabs \\
Anadex & Neolanta & Ultraflu & Fitodiar \\
Paracetin & Gazero & Termorex & Nodiar \\
& Trifed & Konimag & & Kaocitin \\
& & & & Biodiar \\
& & & & Neoenterodiastop \\
& & & Diaend \\
& & & Diarem \\
& & & Omegdiar \\
& & & Primadia \\
& & & Lesdiar \\
\hline
\end{tabular}

OTC: Over the counter

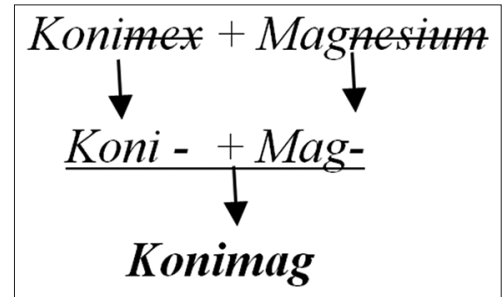

Diagram 1: Over the counter medicine naming with blending of company name and active ingredient

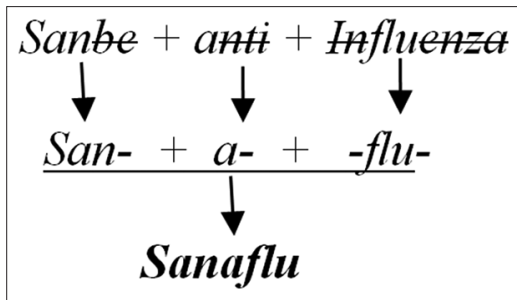

Diagram 2: Over the counter medicine naming with blending of company name and use of the medicine

Lesdiar, Diaend, Diarem, Gazero and Entrostop, Procold, Ultraflu. Diagram 3 shows an example of such blending of OTC medicine naming.

According to product naming strategy, such names are showing what can be obtained by using the product, in line with the product name is designed to inform the usage or function of the product. Therefore, through the name of this product, the company not only provides the identity of the product but also provides information regarding the usefulness of the product. The consumers who will purchase the product know not only the brand of the product but also the usefulness of the purchased product.

Fourth, the OTC medicines above are blending of the active ingredients as the therapeutic substances in the medicine such as Kaocitin is blending of Kaolin and Pektin, Magasida is blending of magnesium and Antasida, then Decolsin, Decolgen, Paracetin, and Trifed. This product naming strategy is just combining words that have joint meaning of product composition through the compounding (Diagram 4).

It describes the active ingredients paracetamol and guaifenesin that can be used as the effective therapeutic substances working as decongestant. Such OTC medicine name indirectly informs to consumers that if they need cough and cold remedies, the precise and accurate medicine is 


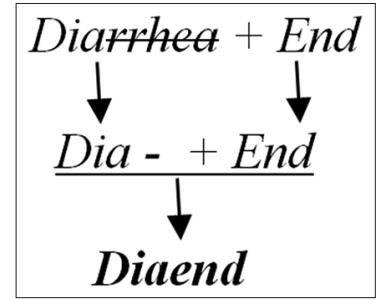

Diagram 3: Over the counter medicine naming with blending of use of the medicine and what can be obtained

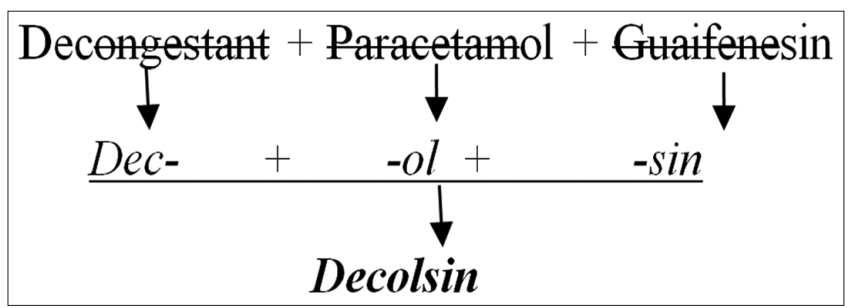

Diagram 4: Over the counter medicine naming with blending of effective therapeutic substance and active ingredients

Table 2: List of OTC medicines with clipping process in product naming

\begin{tabular}{lllll}
\hline Methods & $\begin{array}{l}\text { Cough } \\
\text { and cold }\end{array}$ & Antacid & Influenza & Antidiarrheal \\
\hline Clipping & - & - & Inza & - \\
\hline
\end{tabular}

OTC: Over the counter

Table 3: List of OTC medicines with compounding process in product naming

\begin{tabular}{lllll}
\hline Methods & $\begin{array}{l}\text { Cough and } \\
\text { cold }\end{array}$ & Antacid & Influenza & Antidiarrheal \\
\hline Compounding & $\begin{array}{l}\text { Stop cold } \\
\text { Baby cough }\end{array}$ & - & - & - \\
& & & \\
\hline
\end{tabular}

OTC: Over the counter

decolsin. The weakness of this method is not all consumers understand the function and the active ingredients stated in the name of such OTC medicines.

\section{Clipping}

Among 57 data of OTC medicine, it is only found 1 product name employing clipping product name formation, namely, Inza (Table 2).

The description of Inza formation is as shown in Diagram 5.

The product naming strategy used is syncope namely shortening the word by cutting the middle part of the word. According to the strategy of product naming, it is in line with the effective and informative naming, i.e., easy to pronounce, easy to remember, and indicates the functionality and usability of the product. Therefore, based on the word used as the product name, Inza has the same meaning as influenza. Referring to the meaning, certainly, the company aims to promote to consumers that Inza is the product suitable for influenza remedy. It makes the consumer becomes free of influenza.

\section{Compounding}

Similar to clipping method, compounding method is limitedly found in OTC medicine naming method. From 57 data, it meets only to 2 data as shown in Table 3.

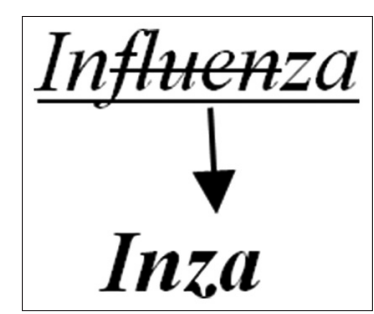

Diagram 5: Over the counter medicine naming with clipping of ailment name

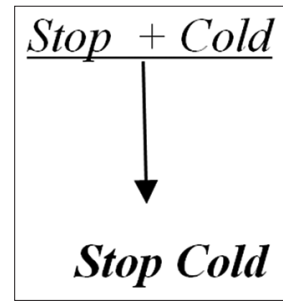

Diagram 6: Over the counter medicine naming with compounding of usefulness and ailment name

In this process of OTC naming, the product name is obtained through the process of word formation called compounding that is formed by combining two words together and produces new meaning. The illustration of word formation of the product is as shown in Diagram 6.

According to the product naming strategy, it is formed as a hyperbole that emphasizes superiority and excellence of the product. In addition, the name of the product is designed to express the usefulness or ability of the product. The company named the product stop cold is certainly intended to promote to consumers that the product has the capability to cure the cold. In addition, this product shows what can be obtained using the product. By using this medicine, the cold is stop or he/she meets a stop cold condition. Stop cold is effective and informative OTC medicine naming since it is easy to pronounce, easy to remember, and indicates the functionality and usability of the product. When someone has cold attack, he/she need medicine to cure or stop it, and then stop cold is the easiest product name to mention. The same product naming strategy for OTC medicine is baby cough which also confirms that the product is identical for curing cough of baby.

\section{Unknown method}

From 57 data of OTC medicine, there are 20 products that do not employ certain methods such as clipping, blending, and compounding but it is formed by creating a new word. There is no linguistic reference regarding the naming of the medicines. Table 4 is the lists of OTC medicines categorized into unknown method.

Initially, they tend to be categorized into coinage, the words formed without the use of methods or other word elements but they are not in line with the statements that the words are formed from existing ones and usually words that have been popular and is intended to maintain the popularity of the word or to make it more popular since they do not exist and have not been popular formerly. Therefore, there is no clear reference linguistically. According to product naming strategy, although they are easy to pronounce and easy to remember, but they do not represent effective and informative product naming since they do not indicate the functionality and usability of the product.

In the level of practical information, they also do not have a denotative function which directs consumers to identify what OTC medicine to buy. On the connotative level, do not raise the image of the products. Therefore, to popularize such OTC medicine names, more efforts of promotion is seemly required than the ones with effective and informative naming. 
Table 4: List of OTC medicines with unknown method in product naming

\begin{tabular}{lllll}
\hline Method & $\begin{array}{l}\text { Cough and } \\
\text { cold }\end{array}$ & Antacid & Influenza & Antidiarrheal \\
\hline Unknown & Ersylan & Waisan & Poldan Mig & Norit \\
& Oskadryl & & Neozep & \\
& Dorbigot & & Oskadon & \\
Intunal & & Mixagrip & \\
& Panadol & & \\
& Refagan & & \\
& Tera F & & \\
& Komix & & \\
& Mextril & & \\
& Mixadin & & \\
& Lafalos & & \\
& Bisolvon & & \\
& Mucoangin & & \\
& Mucosolvan & & \\
\hline
\end{tabular}

OTC: Over the counter

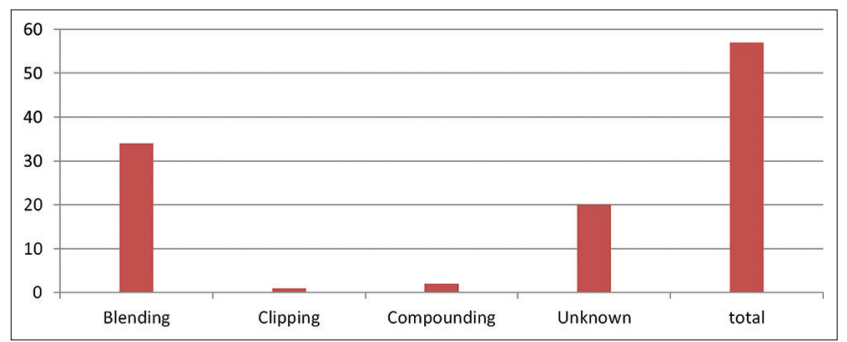

Fig. 1: Description of over the counter medicine naming in Indonesia

\section{CONCLUSION}

It is clearly revealed that an effective and informative OTC medicine naming uses linguistics and product naming strategies properly and accurately. From the data, represented by 57 taken-randomly OTC medicine names in Indonesia, as many as $59.6 \%$ (34 products) using blending naming, $1.7 \%$ (1 product) using clipping, 3.5\% ( 2 products) using compounding, and 35\% (20 products) using unknown method. In the context of product naming strategies, $65 \%$ of the data employs superiority and product advantage emphasizes, usability or ability conducted by the product, and showing what can be obtained by using the product. While the remains $35 \%$ does not employ the product naming strategies properly except easy to pronounce. Fig. 1 describes the distribution of OTC medicine product naming methods.

Since the unknown method OTC medicine naming cannot be easily identified from their names, it can cause disadvantages for both consumer and producer. The consumers find difficulty in identifying the OTC medicine name in that case it could be less marketable. On the other hand, the producer cannot promote their product through the names of the OTC medicine directly, and consequently, it should be assisted by its label and more promotion which means higher cost of promotion should be prepared by the company.

\section{REFERENCES}

1. Pamungkas K. Word formation and product naming strategy: A study of morphology. The role of indigenous languages in constructing identity. In: Purwoko H, Subiyanto A, Sayekti W, Pasaribu T, Thianto Y, Sarmah P, editors. Proceeding of the $5^{\text {th }}$ International Conference Lamas Undip; 2015, September 2-3. Master Program in Linguistics Diponegoro University in Collaboration with Balai Bahasa Provinsi Jawa Tengah (Indonesia); 2015. p. 108-12.

2. Marchand H. The Categories and Types of Present-Day English Word Formation. $2^{\text {nd }}$ ed. Munich: C. H. Becksche Verlaegsbuchhandlung; 1992.

3. McManish C, Stollenwerk D, Sheng Z. Ed. Language Files. United States of America: Advocate Publishing Group; 1998.

4. Katamba F. Morphology. Hampspire: The Mac Millan Press Ltd.; 1993. p. 354 .

5. Danesi M. Messages, Signs, and Meanings: A Basic Textbook in Semiotics and Communication. $3^{\text {rd }}$ Ed. Toronto: Canadian Scholars' Press, Inc.; 2004.

6. Ishak M, Koh S. Advertising-question and answer. Singapore: Brighton Publication; 1992.

7. U. S. Food and Drug Administration. Available from: http://www.fda. govDrugs/ResourcesForYou/Consumers/BuyingUsingMedicineSafely/ UnderstandingOvertheCounterMedicines/Choosing the right over the countermedicineOTCs/ucm150299.html.

8. Kridalaksana H. Kamus Linguistik. $3^{\text {rd }}$ ed. Jakarta: Gramedia Pustaka Utama; 2001.

9. Aronoff M, Fudeman K. What is Morphology? $2^{\text {nd }}$ ed. United Kingdom: Wiley-Blackwell; 2011. p. 312.

10. Nunan D. Research Methods in Language Learning. Cambridge: CUP; 1992

11. Cook G. The Discourse of Advertising. London: Routledge; 1992. 